\title{
Blending in heterosyllabic consonant clusters in three Catalan dialects
}

\author{
Daniel Recasens
}

Universitat Autònoma de Barcelona and Institut d'Estudis Catalans, Barcelona

This study is an electropalatographic investigation of clusters composed of $/ \mathrm{n} /$ or $/ \mathrm{l} /$ followed by the (alveolo)palatal consonants $/ K, \mathrm{j} /$ or by dental $/ \mathrm{t} /$ in three Catalan dialects, i.e., Majorcan, Valencian and Eastern. Data show that articulatory blending through superposition occurs in the palatalizing environment except when $\mathrm{C} 1$ is highly constrained (e.g., dark /1/) or C2 is purely palatal and therefore, produced at a distant articulatory location from $\mathrm{C} 1$. Contrary to previous descriptions in the literature, data for $/ \mathrm{nt}$, lt/ reveal that blending through superposition rather than assimilation is at work. The implications of these data for theories of speech production are discussed.

\section{Introduction}

This study seeks to explore whether the DAC model of coarticulation may account satisfactorily for blending processes in clusters composed of front lingual consonants produced with the tongue tip, blade and predorsum, i.e., dentals or dentoalveolars, alveolars and alveolopalatals. It presents experimental data on C-to-C adaptation mechanisms in place of articulation for thirteen speakers of three Catalan dialects, i.e., Majorcan, Valencian and Eastern, and has a much larger scope than previous studies dealing with data for fewer speakers of the Eastern dialect only (Recasens and Pallarès, 2001, Recasens, 2006).

According to the DAC model (Recasens, Pallarès and Fontdevila, 1997, Recasens and Pallarès, 2001), the articulatory realization of consonant clusters is conditioned by the degree of articulatory constraint for the consonants in the cluster, i.e., by the requirements that speakers impose on the articulatory structures for the formation of a consonant closure or constriction. The alveolar trill $/ \mathrm{r} /$, the alveolar and alveolopalatal fricatives $/ \mathrm{s} /$ and $/ \mathrm{J} /$ and dark $/ \mathrm{l} /$ appear to be more constrained than oral and nasal stops, i.e., the dental / $\mathrm{t} /$, the alveolar $/ \mathrm{n} /$ 
and the alveolopalatals $/ \mathrm{n} /$ and $/ K /$. Indeed, in comparison to the latter consonants, the former ones are more resistant to change and exert more prominent effects on other consonants in line with the precise aerodynamic and articulatory mechanisms involved (Solé, 2002). The alveolar lateral /1/ is not equally dark in all Catalan dialects: it is strongly dark in Majorcan, moderately dark in Eastern and clear in Valencian. The DAC model postulates that the degree of articulatory constraint for /1/ should increase with darkness degree in view of the strict demands involved in performing a postdorsal approximation in addition to an apical closure for the dark but not for the clear variety.

Differences in degree of constraint among Catalan consonants keep a certain relationship with place of articulation. Thus, in Eastern Catalan, the two highly constrained lingual fricatives $/ \mathrm{s}, \mathrm{S} /$ and the trill $/ \mathrm{r} /$ are invariably centroalveolar or postalveolar, while the less constrained consonants $/ \mathrm{t}, \mathrm{n} /$ are more anterior, i.e., $/ \mathrm{t} /$ is fixedly dental and $/ \mathrm{n} /$ may be articulated at the front alveolar zone. Closure for the alveolopalatals $/ K /$ and $/ \mathrm{n} /$ may occur simultaneously at the back alveolar zone and at the prepalate, but also just at the alveolar or dentoalveolar zone in the case of $/ K /$ (Recasens and Espinosa, 2006). The two varieties of $/ 1 /$ are anterior, more so in Majorcan (dental or dentoalveolar) than in Eastern and Valencian (front alveolar).

A basic prediction of the DAC model regarding C-to-C adaptation mechanisms in consonant clusters is that highly constrained consonants should prevail upon less constrained ones through an assimilatory action or through robust coarticulatory effects (see also Fowler and Saltzman, 1993). On the other hand, two relatively unconstrained consonants ought to undergo blending and thus, result into a compromise articulatory outcome between the two original consonants in the cluster.

The goal of this study is to verify the validity of the prediction that consecutive consonants which share a similar degree of articulatory constraint and are not highly contrained are realized through a blending mechanism. The articulatory implementation of gestural blending will be investigated in two different scenarios, i.e., in a palatalizing environment in the case of sequences composed of the alveolars $/ \mathrm{n}, 1 /$ followed by the (alveolo)palatals $/ K, \mathrm{n} /$, and in a dentalizing environment in the case of clusters with $/ \mathrm{n}, \mathrm{l} /$ followed by dental $/ \mathrm{t} /$. Different articulatory outcomes are expected to occur in clusters with /1/ depending on whether the consonant is dark or clear (see section 1.1). Several sequences will be excluded from analysis, namely, consonant combinations with $\mathrm{C} 1=/ \mathrm{t} /$ since this consonant often assimilates to a following nasal or lateral in Catalan, and the sequence $/ \mathrm{nj} / \mathrm{which}$ is realized [n:] in all three dialects. 


\subsection{Palatalizing environment}

Two possible blending mechanisms may apply to consonant clusters. A first mechanism occurs when the closure area for the outcoming articulation results from superimposing the closure areas of the two adjacent consonants taken independently. This blending mechanism has been found to operate in clusters with $\mathrm{C} 1=/ \mathrm{n} /$ and, less so, $\mathrm{C} 1=/ 1 /$ and $\mathrm{C} 2=/ \Lambda, \mathrm{n} /$ in Eastern Catalan (Recasens, 2006), and will be referred to as "blending through superposition". In case that clusters composed of $\mathrm{C} 1=/ \mathrm{n}, 1 /$ and $\mathrm{C} 2=/ K, \mathrm{n} /$ exhibit blending through superposition, we expect $\mathrm{C} 1$ to undergo some contact increase at the back closure border since $\mathrm{C} 1$ is dental, dentoalvolar or alveolar while $\mathrm{C} 2$ is alveolopalatal. Moreover, the front closure border should reach a fairly anterior location, mostly due to $\mathrm{C} 1$ in clusters with $\mathrm{C} 2=/ \mathrm{n} /$, and to $\mathrm{C} 1$ and/or $\mathrm{C} 2$ in clusters with $\mathrm{C} 2=/ \Lambda /$.

According to a second production strategy, the blending outcome is realized at an intermediate zone between the places of articulation of $\mathrm{C} 1$ and $\mathrm{C} 2$, and will be referred to as "blending through intermediation". This instance of blending has been reported to take place in the $\mathrm{CV}$ sequence $/ \mathrm{ki} /$ or in consonant clusters such as /t $0 /$ and /sj/ (Browman and Goldstein, 1989, 1992).

While all clusters just referred to undergo blending, its articulatory manifestation may differ depending on the case. More evidence needs to be gathered in order to find out what factors determine the implementation of the two blending types referred to. Two plausible factors are closure or constriction extent for the two adjacent segments and the spatial distance between their places of articulation. Thus, blending through superposition is expected to apply in consonant clusters if the two adjacent consonants are articulated nearby (as for $/ \mathrm{n} /$ and $/ \mathrm{n} /$ ), and at least one of them involves a large degree of contact at closure or constriction location (as for alveolopalatals).

A related issue is the temporal manifestation of blending, i.e., whether the compromise articulation between $\mathrm{C} 1$ and $\mathrm{C} 2$ occurs already at $\mathrm{C} 1$ onset or else at a later point in time during $\mathrm{C} 1$. If blending through palatalization starts at $\mathrm{C} 1$ midpoint or at $\mathrm{C} 1$ offset, the front and back closure location at the onset of $\mathrm{C} 1=/ \mathrm{n}, 1 /$ should be more anterior than the closure location for the alveolopalatals $\mathrm{C} 2=/ K, \mathrm{n} /$. Therefore, we would be facing a palatalized alveolar rather than an alveolopalatal realization at this temporal period (e.g., $\left[\mathrm{n}^{\mathrm{j}}\right]$ in the case of the cluster $/ \mathrm{n} K /$ ).

The conditions preventing blending from taking place completely or partially will also be paid attention to. In principle, blending may fail to apply if the two adjacent consonants in the cluster involve distant articulatory targets, as when $\mathrm{C} 2$ is purely palatal rather than alveolopalatal (e.g., /n/ for some Majorcan speakers). It could also be delayed or absent in clusters with $\mathrm{C} 1=/ 1 /$ due to 
requirements on laterality and on darkness, since in both cases the tongue predorsum is relatively lowered in order to allow the passage of airflow through lateral oral channels (for laterality) and to facilitate the achievement of a $/ \mathrm{w} /$-like percept (for darkness).

\subsection{Dentalizing environment}

The articulatory outcome of clusters composed of $\mathrm{C} 1=/ \mathrm{n}, 1 /$ and $\mathrm{C} 2=/ \mathrm{t} /$ is hard to ascertain. The traditional view is that place assimilation is at work here and therefore, alveolars should acquire the dental place for $/ \mathrm{t} /$ throughout the entire closure period (see, for example, Navarro Tomás, 1972 for Spanish). Within the DAC model framework, the fact that all those consonants are relatively unconstrained and produced at the same or at a close articulatory zone renders the implementation of blending possible as well.

\section{Methodology}

\subsection{Recording procedure}

Linguopalatal contact configurations and acoustic data were gathered synchronously with the Reading electropalatography (EPG) system every $10 \mathrm{~ms}$ using artificial palates equipped with 62 electrodes. Acoustic data were digitized at $10 \mathrm{kHz}$.

Recordings included the clusters $/ \mathrm{nt}, \mathrm{n} K, \mathrm{tt}, 1 \kappa, 1 \mathrm{n} /$ occurring across a word boundary embedded in meaningful sentences four to six syllables long, e.g., /nt/ in the sentence "d'anys en té set" ("he/she is seven years old"), $/ \mathrm{n} K /$ in the sentence "això no enllaça" ("this does not work out well"). These clusters were recorded seven times by the five male Majorcan speakers AR, BM, MJ, ND and $\mathrm{CA}$, seven times by the five male Valencian speakers JM, VB, MS, VG and AV, and a variable number of times by the three male Eastern speakers DR (five times) and JP and JS (three times). The cluster $/ 1 K /$ was not recorded by the Valencian subjects.

Data were also processed for single $/ \mathrm{t}, \mathrm{n}, \mathrm{l}, \kappa, \mathrm{n} /$ in (quasi-)symmetrical VCV sequences in the context of front, low and back rounded vowels in order to determine the extent to which closure location in clusters differs from closure location in intervocalic position. VCV recordings were only carried out for $/ \mathrm{t}, \mathrm{n}$, 1/ in Majorcan and Valencian, and for / $\mathrm{t} /$ in Eastern, e.g., /iti/ in "aprèn l'hitita" ("learn the Hittite language"), /ata/ in "beu-te la tassa" ("drink what is in the cup"), /otu/ in "el llapis rotula" ("the pencil works"). Data for intervocalic /n, 1/ in Eastern and for intervocalic $/ K, \mathrm{n} /$ in the three dialects were taken from mean 
contact patterns across the three contextual vowels published elsewhere (see Recasens and Pallarès, 2001).

The EPG data could not be processed for $/ 1 K /$ for any of the Valencian speakers and for the Eastern speaker JP because /1/ assimilated to following $/ \mathrm{K} /$ in this case, and for $/ \mathrm{lt}, 1 \kappa, \mathrm{ln} /$ for speaker AR since he vocalized preconsonantal /1/ almost systematically.

\subsection{Measurement criteria}

All cluster tokens were submitted to articulatory analysis. Closure or constriction location was measured on linguopalatal contact patterns placing a cursor on simultaneous EPG, spectrographic and waveform displays using the MultiSpeech 3700 program of Kay Pentax.

The linguopalatal contact patterns under analysis show 62 electrodes distributed into eight horizontal rows and four vertical columns at each side of the palate surface (see Figure 1). Filled electrodes have been contacted by the tongue while empty ones have not. Electrodes are grouped into two major articulatory zones, alveolar at rows 1 through 4, and palatal at rows 5 through 8 . Several articulatory subzones were identified for better data interpretation, namely, dental (exclusively at row 1, just behind the upper teeth), dentoalveolar (at rows 1-2, 1-3 or 1-4), centroalveolar and postalveolar (at rows 2-3 and 3-4, respectively), alveolopalatal (at a continuous contact area encompassing the alveolar rows 1 through 4 and the palatal rows 5 through 8), prepalatal (at row 5), mediopalatal (at rows 6-7) and postpalatal (at row 8).

\section{$\mathrm{C} 1 \mathrm{C} 2 \mathrm{C} 3 \mathrm{C} 4 \mathrm{C} 4 \mathrm{C} 3 \mathrm{C} 2 \mathrm{C} 1$}

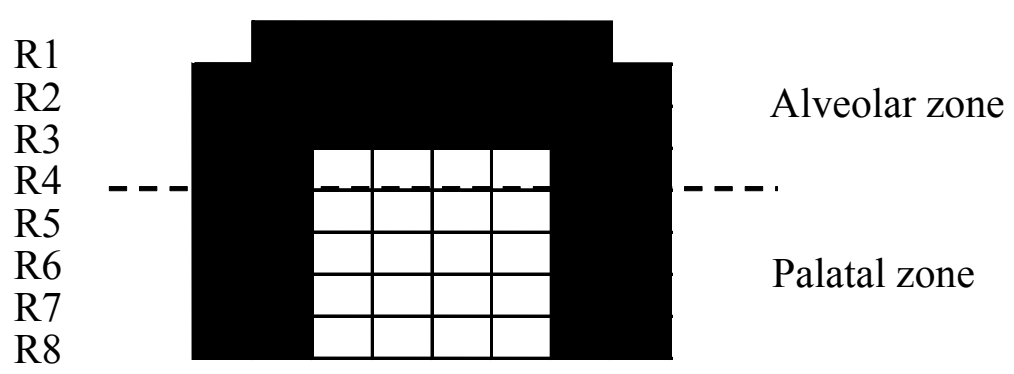

Figure 1. Linguopalatal contact configuration with 62 electrodes distributed into rows (R1-R8), symmetrical columns (C1-C4) and articulatory zones (alveolar, palatal).

For $/ \mathrm{t}, \mathrm{n}, \kappa, \mathrm{n} /$, the consonant was taken to last from the onset of a complete closure until the release of any of the central electrodes. In the case of $/ 1$, consonant onset and offset were determined by the presence or absence, 
respectively, of at least one of the two centralmost alveolar electrodes. The application of this articulatory criterion was assisted by inspection of spectrographic displays.

Place of articulation was measured at several temporal points during $\mathrm{C} 1$ and $\mathrm{C} 2$ so as to explore the temporal extent of the C-to-C adaptation effects: at $\mathrm{C} 1$ onset, midpoint and offset, and at $\mathrm{C} 2$ onset and midpoint. Place of articulation for the intervocalic consonants was measured at consonant midpoint.

Two values corresponding to maximal contact activation at the front and back closure borders were taken at each point in time, e.g., 1-2 or 2-4 whenever full electrode activation occurred at rows 1 and 2 (in the former case) or at rows 2, 3 and 4 (in the latter case). For a given row, maximal activation was considered to apply whenever lingual contact occurred at all its electrodes, at all its electrodes except for one of the two central ones, or just at its two central electrodes. Both borders were assigned the same value if maximal activation turned out to be present at a single row. Closure fronting values for the intervocalic consonants were determined according to the same criterion and averaged across vowel contexts.

Front and back closure location values for consonant clusters were compared with those for the two consonants in intervocalic position in order to find out whether the final articulatory outcome was arrived at through blending through superposition or through blending through intermediation in the palatalizing environment, and through assimilation or through any of the two blending processes in the dentalizing environment. Initially, we carried out ANOVAs with repeated measures using the same conditions referred to below with one averaged score per condition for each speaker. Results were discouraging since significance was achieved in very few instances due perhaps to the small size of the data set and to the fact that the original data proceeded in one unit steps and therefore, were not actually continuous (see above). For this reason, we will provide results obtained from regular ANOVAs performed on data for all tokens and speakers. Statistical comparisons between the back closure location values for the clusters $/ \mathrm{nt}, 1 \mathrm{t} /$ and for intervocalic $/ \mathrm{n}, 1, \mathrm{t} /$ were carried out with 'consonant condition' as the only factor and three levels of the independent variable, i.e., ' $/ \mathrm{n} / \mathrm{in}$ the cluster $/ \mathrm{nt} /$ ' or ' $/ 1 /$ in the cluster $/ 1 \mathrm{t} /$ ', 'intervocalic $/ \mathrm{n} /$ ' or 'intervocalic $/ 1 /$ ', and 'intervocalic $/ \mathrm{t} /$ '. Data for the intervocalic consonants were compared statistically with those for the clusters at $\mathrm{C} 1$ midpoint and at $\mathrm{C} 1$ offset but not with data at $\mathrm{C} 1$ onset since closure location at this temporal point was fairly anterior and did not reflect the implementation of a blending mechanism. Statistical comparisons for Eastern Catalan involved data for intervocalic $/ \mathrm{t} /$ but not data for intervocalic $/ \mathrm{n}, 1 /$ since there were not multiple tokens of the last two consonants in intervocalic position in this dialect. 
Bonferroni post-hoc tests were run on the significant main effects whenever appropriate and the degree of significance was set at $p<0.05$.

\section{Results}

\subsection{Palatalizing environment}

Figure 2 plots the front and back closure border trajectories averaged across tokens and speakers for clusters composed of $\mathrm{C} 1=/ \mathrm{n}, 1 /$ and $\mathrm{C} 2=/ K, \mathrm{n} /$ (thick lines), and for those same consonants in intervocalic position (discontinuous straight lines for $\mathrm{C} 1$, continuous straight lines for $\mathrm{C} 2$ ).

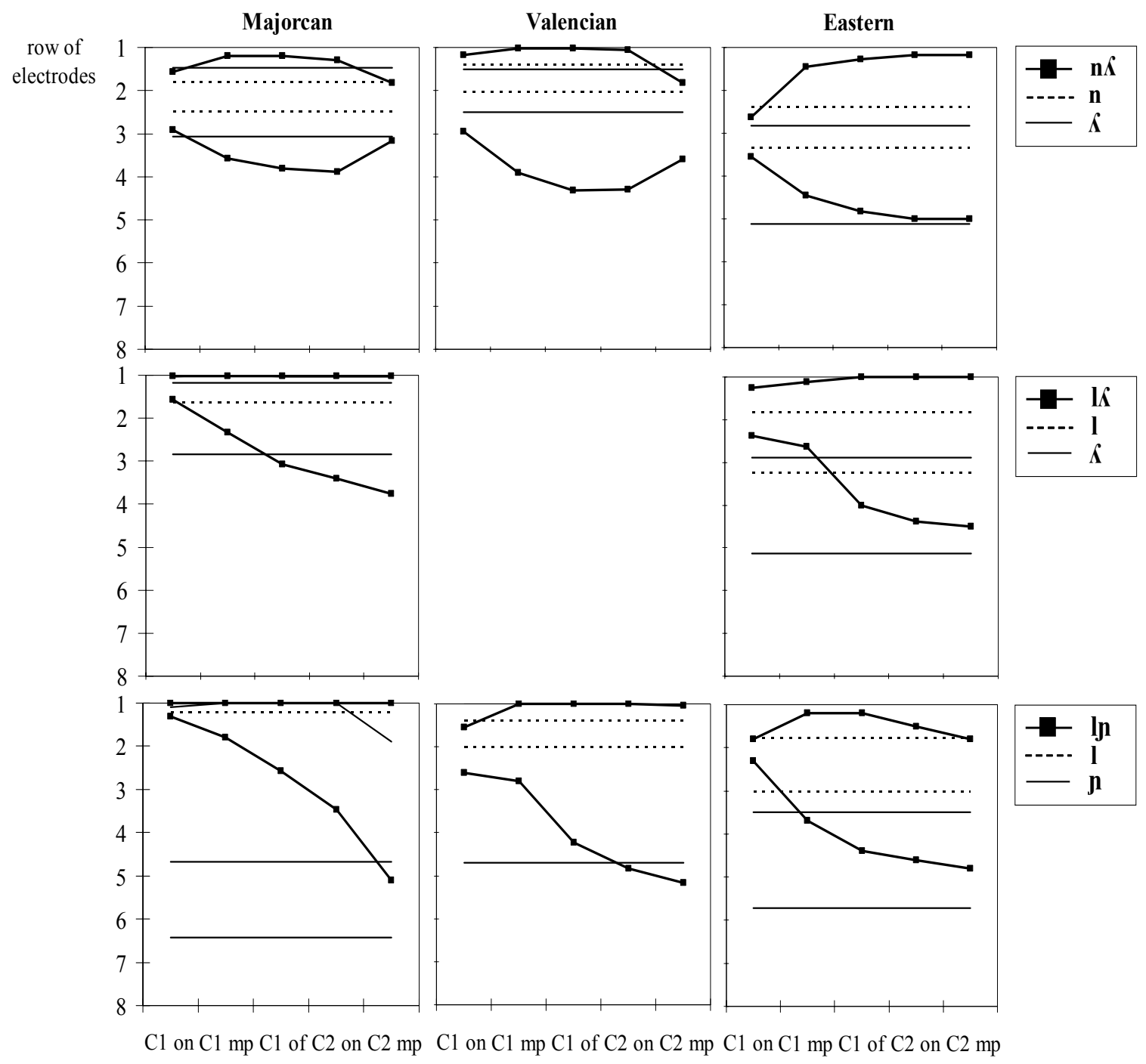

Figure 2. Front and back closure border location at $\mathrm{C} 1$ onset, midpoint and offset and at $\mathrm{C} 2$ onset and midpoint for the clusters $/ \mathrm{n} K /$ (top), $/ 1 K /$ (center) and $/ \mathrm{ln} /$ (bottom). Closure location at both borders for intervocalic /n, 1/ (discontinuous straight lines) and intervocalic $/ K, \mathrm{n} /$ (continuous straight lines) is also given. Data correspond to averages across tokens and speakers. 
Straight lines for the intervocalic consonants show that /n, 1/ are generally articulated somewhere at the central area of the alveolar zone except for strongly dark /1/ in Majorcan which is articulated at row 1 only and therefore, exhibits probably a dental articulation. Regarding intervocalic $/ K, \mathrm{n} /$, the lateral is basically alveolar in Majorcan and Valencian and alveolopalatal in Eastern, while the nasal is alveolopalatal in Valencian, alveolopalatal or prepalatal in Eastern and purely palatal in Majorcan.

For all clusters, thick lines reveal that closure extent is restricted to a relatively small contact area at $\mathrm{C} 1$ onset and expands posteriorly to the back border as $\mathrm{C} 2$ is approached. This backward expansion movement often yields a comparable closure area to that for the second consonant in the cluster, and it occurs earlier in clusters with $\mathrm{C} 1=/ \mathrm{n} /$ (at about $\mathrm{C} 1$ midpoint) than in those with $\mathrm{C} 1=/ 1 /$ (at about $\mathrm{C} 1$ offset). It applies to a lesser extent to strongly dark /1/ in Majorcan than to clear/1/ in Valencian and to moderately dark /1/ in Eastern. Therefore, it appears that the laterality and darkness degree in /1/ delay and may block the palatalization effect. An increase in contact at the front border often reaches row 1 already during the first half of the alveolar nasal and the alveolar lateral in all consonant combinations.

As a general rule, closure location at $\mathrm{C} 1$ onset is fairly front and resembles that for $/ \mathrm{n}, 1 /$ rather than that for $/ \mathrm{n}, K /$. Accordingly, dialect-dependent differences in closure anteriority at $\mathrm{C} 1$ onset match those found for the same consonants in intervocalic position, i.e., fronting decreases in the progression Valencian, Majorcan $>$ Eastern for $/ \mathrm{n} /$ and with darkness degree in the progression Majorcan $>$ Valencian, Eastern for $/ 1 /$.

As pointed out in the Introduction, an open issue is whether blending is implemented through the superposition of the closure areas for $\mathrm{C} 1$ and $\mathrm{C} 2$ such that the outcoming realization encompasses them, or else through the achievement of an intermediate closure location between the closure areas for the two consonants.

According to data for Majorcan and Valencian in the top graphs of Figure 2, contact degree at the front and back closure borders is greater at $\mathrm{C} 1$ midpoint and offset for the cluster $/ \mathrm{n} K /$ than for $/ \mathrm{n} /$ and $/ K /$ in intervocalic position. In Eastern Catalan, contact extent runs more anteriorly for $/ \mathrm{n} K /$ than for intervocalic $/ \mathrm{n} /$ and $/ K /$ at the front closure border; as for the back closure border, the contact trajectory for $/ \mathrm{n} K /$ runs more posteriorly than that for intervocalic $/ \mathrm{n} /$, and approaches but does not quite reach that for intervocalic $/ K /$ until at about C2. Inspection of the individual speakers' data (not shown) reveals that a closure area generally greater than or, less so, equal to that predicted by blending through superposition occurs at $\mathrm{C} 1$ midpoint for all Majorcans, all Valencians and the Eastern speaker DR. The Eastern speakers JP and JS, on the other hand, 
show an intermediate closure location between that for $\mathrm{C} 1$ and $\mathrm{C} 2$ all throughout the cluster when the front and back closure borders are taken into consideration.

Regarding clusters with $\mathrm{C} 1=/ 1 /$ in the graphs located at the center and bottom of the figure, data for the back closure border indicate that blending through superposition is not reached until about $\mathrm{C} 1$ offset in the case of $/ 1 \mathrm{~K} /$ in Majorcan. This is so for most speakers (BM, MJ, CA), while others achieve blending already at $\mathrm{C} 1$ midpoint (ND). On the other hand, data for the back closure border for $/ 1 K /$ in Eastern and for $/ \mathrm{l} \mathrm{n} /$ in Valencian and Eastern reveal that the two adjacent consonants blend essentially into articulatory configurations which are intermediate between those for intervocalic $\mathrm{C} 1$ and for intervocalic C2. This strategy is found for most speakers $(/ 1 K /, D R, / 1 \mathrm{n} / \mathrm{JM}, \mathrm{VB}$, MS, VG, DR, JP, JS), while others prefer blending through superposition either at $\mathrm{C} 1 \mathrm{midpoint}(/ \mathrm{ln} /, \mathrm{AV})$ or at $\mathrm{C} 1$ offset $(/ 1 \mathrm{~K} / \mathrm{JS})$. In all cases, the front closure border for clusters $/ 1 \kappa, 1 \mathrm{n} /$ reaches maximal fronting at row 1 early in the cluster.

A particular strategy applies to the cluster /ln/ in Majorcan (see bottom left graph of Figure 2), where the back closure border for $\mathrm{C} 1=/ 1 /$ extends more posteriorly than that for intervocalic /1/ but falls short of the front closure border for intervocalic $/ \mathrm{n} /$. Data for the individual speakers reveal that there is often a very large articulatory distance between the closure targets for the two consonants $/ 1 /$ and $/ \mathrm{n} /$ in intervocalic position, i.e., dark $/ 1 /$ is essentially dental or front dentoalveolar, while closure for $/ \mathrm{n} /$ may cover the prepalate and mediopalate (MJ), the entire palatal zone (CA) or just the back palate (BM, ND). This may account for why it may take so long for the articulatory target for $\mathrm{C} 2=/ \mathrm{n} /$ in the cluster $/ \mathrm{l} / \mathrm{n}$ to be reached and why, just as in Figure $2, \mathrm{C} 1=/ 1 /$ in this cluster exhibits an intermediate realization between intervocalic $/ 1 /$ and $/ \mathrm{n} /$ in the case of speakers BM, MJ and CA. Data for speaker CA, for whom $/ 1 /$ is strongly dark and intervocalic $/ \mathrm{n} /$ is alveolopalatal, reveal the presence of carryover effects involving depalatalization and thus, of palatal contact loss during C2. Speaker ND (whose data have not been averaged with those for the other three speakers in the figure) shows two separate targets and no gestural overlap for the two consonants in the cluster, i.e., the tongue travels fast from the alveolar zone at $/ 1 /$ offset to the postpalatal zone at $/ \mathrm{n} /$ onset.

\subsection{Dentalizing environment}

\subsubsection{General trends}

Data reported in Figure 3 allow investigating whether clusters with $\mathrm{C} 1=/ \mathrm{n}, 1 /$ and $\mathrm{C} 2=/ \mathrm{t} /$ undergo regressive assimilation or blending. Closure border location values for intervocalic /n, 1/ are identical to those appearing in Figure 2. As for intervocalic $/ t$, the continuous straight lines in Figure 3 indicate that the front 
closure border for this consonant reaches row 1 at the teeth, while the degree of alveolar fronting at the back closure border varies according to dialect in the progression Valencian $>$ Majorcan $>$ Eastern.

In view of the closure location characteristics for $/ \mathrm{t}, \mathrm{n}, \mathrm{l} /$ in intervocalic position and for $/ \mathrm{nt}$, $1 \mathrm{t} /$, the following processes of segmental adaptation may be predicted to occur in the two clusters:

(a) Regressive assimilation should apply whenever the back closure border is more anterior for intervocalic $/ \mathrm{t} /$ than for intervocalic $/ \mathrm{n} / \mathrm{or} / \mathrm{l} /$, and that for the cluster is not more retracted than that for $/ \mathrm{t} /$. In this particular case it may be claimed that $\mathrm{C} 1$ exhibits the same closure location as $\mathrm{C} 2$ in the clusters /nt, lt/ because place regressive assimilation is at work. As mentioned in the Introduction, regressive place assimilation should involve the presence of the $\mathrm{C} 2$ place of articulation during the entire $\mathrm{C} 1$ closure period and thus, from $\mathrm{C} 1$ onset until $\mathrm{C} 1$ offset.

(b) Blending through intermediation between $\mathrm{C} 1$ and $\mathrm{C} 2$ should take place whenever the back closure border for the cluster occurs about halfway between the back closure border location for the two adjacent consonants in intervocalic position.

(c) Blending through superposition is expected to occur when the closure area for the cluster exceeds the closure area for its two consonants in intervocalic position, or equals that for intervocalic $/ \mathrm{n} /$ or $/ 1 /$ if the back closure border for these two realizations extends more posteriorly than that for intervocalic $/ \mathrm{t} /$.

Data for the mean front closure border trajectories for clusters in Figure 3 (thick lines) are in agreement with those for the individual speakers in showing an anteriormost location at row 1 all along $\mathrm{C} 1$ and $\mathrm{C} 2$. This outcome could be indicative of regressive assimilation (maximal fronting is also found for $\mathrm{C} 2=/ \mathrm{t}$ / in intervocalic position), but is also compatible with a blending account (maximal fronting could result from the superposition of a maximally front dental $\mathrm{C} 2$ and a more retracted alveolar $\mathrm{C} 1$ ).

Relevant variations in contact placement over time for the clusters /nt, lt/ occur at the back closure border. As shown in Figure 3, there is some backward expansion from $\mathrm{C} 1$ onset to $\mathrm{C} 1$ midpoint and $\mathrm{C} 1$ offset which may be considered a general articulatory characteristic of stop closures towards the expansion of their area as consonant midpoint is approached. 


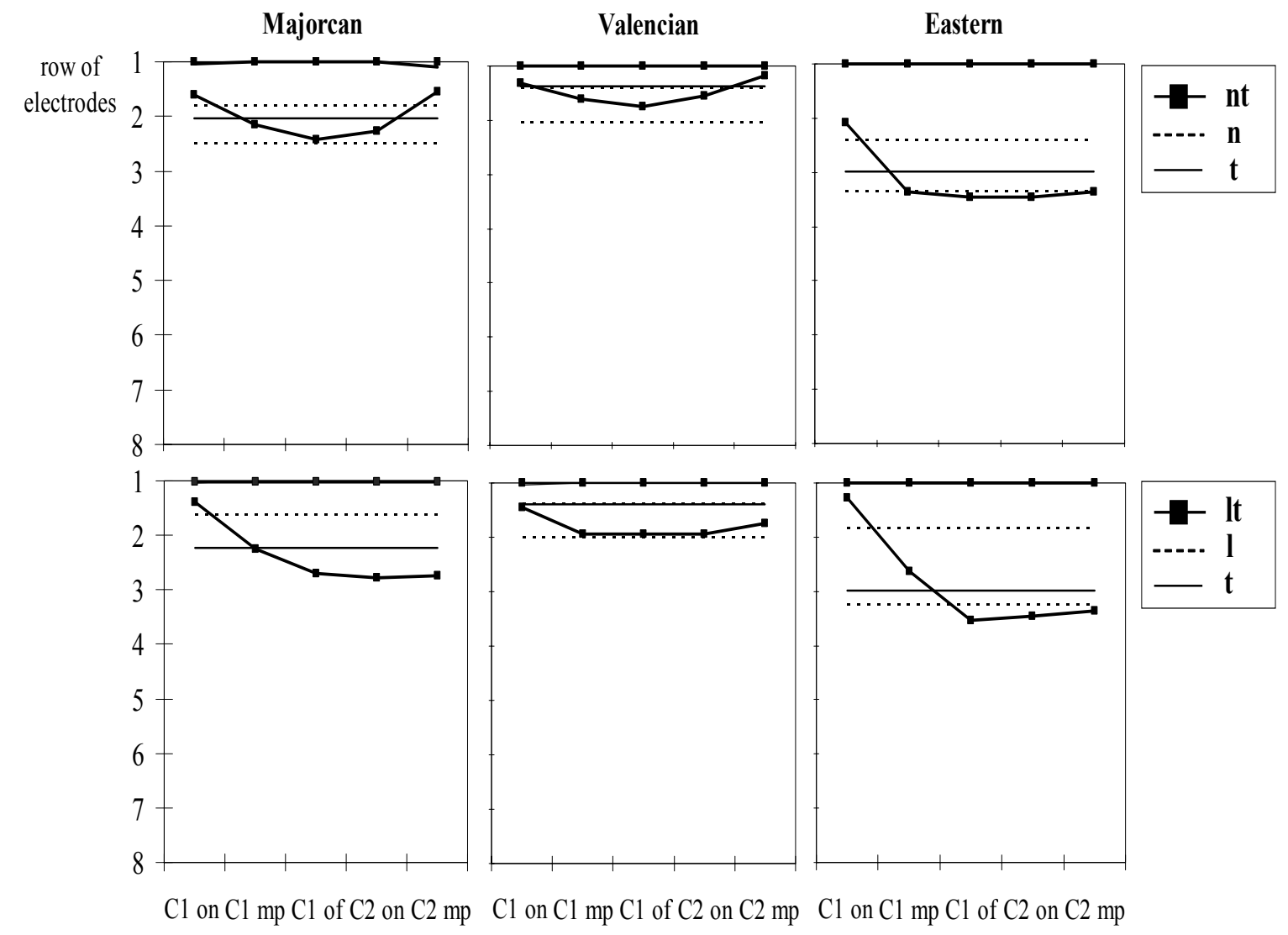

Figure 3. Front and back closure border location at $\mathrm{C} 1$ onset, midpoint and offset and at $\mathrm{C} 2$ onset and midpoint for the clusters /nt/ (top) and /lt/ (bottom). Closure location at both borders for intervocalic /n, $1 /$ (discontinuous straight lines) and intervocalic /t/ (continuous straight lines) is also given. Data correspond to averages across tokens and speakers.

ANOVAs on the back closure border data for /nt/ yielded a significant main 'consonant condition' effect at $\mathrm{C} 1$ midpoint and offset in Majorcan $(\mathrm{F}(2,276)=$ 9.68, $\mathrm{p}=0.000 ; \mathrm{F}(2,276)=9.78, \mathrm{p}=0.000)$ and Valencian $(\mathrm{F}(2,269)=29.51$, $\mathrm{p}=0.000 ; \mathrm{F}(2,269)=25.99, \mathrm{p}=0.000)$. According to the results from post-hoc tests, Majorcan favors blending through superposition at $\mathrm{C} 1$ offset where closure is more retracted for $/ \mathrm{nt} /$ and for intervocalic $/ \mathrm{n} /$ than for intervocalic $/ \mathrm{t} /$, and $/ \mathrm{nt} /$ and intervocalic $/ \mathrm{n} /$ do not differ significantly in the degree of closure fronting. Valencian, on the other hand, favors blending through intermediation also at $\mathrm{C} 1$ offset where closure fronting decreases significantly in the progression $/ \mathrm{t} />/ \mathrm{nt} /$ $>/ \mathrm{n} /$. Contact trajectories in Figure 3 are in accordance with these statistical results. Regarding Eastern Catalan, ANOVAs yielded non-significant effects between /nt/ and intervocalic / $\mathrm{t} /$ at $\mathrm{C} 1$ midpoint and at $\mathrm{C} 1$ offset. Data for this dialect in the figure suggest that the cluster /nt/ and the two intervocalic consonants $/ \mathrm{n} /$ and $/ \mathrm{t} /$ exhibit a similar degree of closure fronting which renders the cluster production strategy ambiguous: there could be regressive assimilation 
since the back closure border location for $\mathrm{C} 1=/ \mathrm{n} /$ in the cluster is comparable to that for intervocalic $/ t /$, but also blending through superposition since the closure area for $\mathrm{C} 1=/ \mathrm{n} /$ is equivalent to the closure areas for intervocalic $/ \mathrm{n} /$ and $/ \mathrm{t} /$.

ANOVAs on the back closure border data for /lt/ yielded a significant main effect of 'consonant condition' at cluster midpoint and offset in Majorcan $(\mathrm{F}(2$, $219)=10.66, \mathrm{p}=0.000 ; \mathrm{F}(2,219)=19.09, \mathrm{p}=0.000)$ and Valencian $(\mathrm{F}(2,237)=$ 29.30, $\mathrm{p}=0.000 ; \mathrm{F}(2,237)=28.66, \mathrm{p}=0.000)$, and at closure midpoint but not at closure offset in Eastern $(F(1,84)=4.82, p=0.03)$. Post-hoc tests reveal that Majorcan favors blending through superposition at closure offset where the back closure border is more posterior for / $1 \mathrm{t} / \mathrm{than}$ for both intervocalic $/ 1 /$ and $/ \mathrm{t} /$ (closure fronting values decrease in the progression $/ 1 />/ t />/ 1 \mathrm{t} /$ in this case). Valencian also favors blending through superposition at $\mathrm{C} 1$ midpoint and offset since the back closure border is more retracted for intervocalic /1/ and for the cluster /lt/ than for intervocalic / $/$ / at both temporal points. Statistical comparisons between data for / $1 \mathrm{t} /$ and for intervocalic / $\mathrm{t} / \mathrm{suggest}$ that Eastern Catalan favors blending through superposition at $\mathrm{C} 1$ offset since /lt/ becomes significantly more posterior than $/ \mathrm{t} / \mathrm{at}$ this temporal point. Data on the back closure border trajectories for this dialect in Figure 3 show that /lt/ could also be more retracted than intervocalic $/ 1 /$.

In summary, results from ANOVAs and inspection of contact trajectories in Figure 3 reveal that the cluster $/ 1 \mathrm{t} /$ is implemented through blending through superposition in most cases. Blending appears to be the preferred production mechanism for the cluster $/ \mathrm{nt} /$ as well.

\subsubsection{Individual speakers}

A more thorough insight into the production mechanisms of the sequences $/ \mathrm{nt}$, 1t/ may be gained from an analysis of the data for the individual speakers. Tables 1 and 2 present front and back closure border location values at $\mathrm{C} 1$ onset, midpoint and offset for /nt/ and /lt/ according to all Majorcan, Valencian and Eastern speakers (right panel), and at consonant midpoint for $/ \mathrm{n} /$ or $/ 1 /$ and for $/ \mathrm{t} /$ in intervocalic position (left and central panels). Thus, for example, data for intervocalic $/ \mathrm{n} /$ and $/ \mathrm{t} /$ and for $/ \mathrm{n} /$ in the cluster $/ \mathrm{nt} /$ for speaker ND reveal that consonant closure in the cluster extends from row 1 (front border) to somewhere between rows 3 and 4 (3.36), while closure for the two intervocalic consonants spans from the same or a more retracted location at the front border $(2.4 \mathrm{for} / \mathrm{n} /$, 1 for $/ \mathrm{t} /$ ) to a slightly more anterior location at the back border (about 3.1 for both $/ \mathrm{n} /$ and $/ \mathrm{t} /$ ).

The closure fronting values for intervocalic $/ \mathrm{n}, 1, \mathrm{t} /$ will be compared with those at the midpoint and offset of $\mathrm{C} 1$ in the two clusters $/ \mathrm{nt}$, lt/ but not with those at $\mathrm{C} 1$ onset since blending does not occur at this moment in time yet. 
Standard deviations for the mean values in the tables are generally small, i.e., zero for the front closure border data, and about a fifth of the corresponding mean for the back closure border data.

Table 1: Front border (FCB) and back border (BCB) closure placement values at the midpoint of intervocalic $/ \mathrm{n} /$ and $/ \mathrm{t} /$ (left and middle panels), and at onset, midpoint and offset of $\mathrm{C} 1=/ \mathrm{n} /$ in the cluster $/ \mathrm{nt} /$ (right panel). Data are presented for all speakers of Majorcan, Valencian and Eastern.

\begin{tabular}{|cc|cc|cc|cccccc|}
\hline \multirow{2}{*}{ Dialect } & \multirow{2}{*}{ Speaker } & \multicolumn{2}{|c|}{$/ \mathbf{V n V} /$} & \multicolumn{2}{c|}{$/ \mathbf{V t V} /$} & \multicolumn{2}{c|}{ C1 ons (/nt/) } & \multicolumn{2}{c|}{ C1 mp (/nt/) } & \multicolumn{2}{c|}{ C1 of (/nt/) } \\
& & FCB & BCB & FCB & BCB & FCB & BCB & FCB & BCB & FCB & BCB \\
\hline \multirow{4}{*}{ Majorcan } & AR & 1.95 & 2.24 & 1.00 & 1.19 & 1.00 & 1.07 & 1.00 & 1.21 & 1.00 & 1.36 \\
& BM & 1.43 & 2.38 & 1.00 & 2.14 & 1.00 & 1.27 & 1.00 & 2.00 & 1.00 & 2.00 \\
& MJ & 1.76 & 2.38 & 1.00 & 1.33 & 1.00 & 1.15 & 1.00 & 1.62 & 1.00 & 1.92 \\
& ND & 2.40 & 3.10 & 1.00 & 3.05 & 1.21 & 2.29 & 1.00 & 3.36 & 1.00 & 3.71 \\
& CA & 1.52 & 2.33 & 1.00 & 2.43 & 1.00 & 2.21 & 1.00 & 2.50 & 1.00 & 3.07 \\
\hline \multirow{5}{*}{ Valencian } & JM & 1.12 & 1.62 & 1.00 & 1.00 & 1.00 & 1.00 & 1.00 & 1.00 & 1.00 & 1.00 \\
& VB & 1.33 & 1.70 & 1.00 & 1.00 & 1.00 & 1.00 & 1.00 & 1.00 & 1.00 & 1.00 \\
& MS & 1.24 & 2.24 & 1.00 & 1.71 & 1.00 & 1.93 & 1.00 & 2.43 & 1.00 & 2.93 \\
& VG & 1.62 & 2.33 & 1.00 & 1.43 & 1.00 & 1.14 & 1.00 & 1.64 & 1.00 & 1.79 \\
& AV & 1.55 & 2.00 & 1.00 & 1.71 & 1.00 & 1.50 & 1.00 & 1.93 & 1.00 & 2.00 \\
\hline \multirow{2}{*}{ Eastern } & DR & 1.33 & 3.00 & 1.00 & 3.60 & 1.00 & 1.80 & 1.00 & 3.60 & 1.00 & 3.80 \\
& JP & 2.83 & 3.83 & 1.00 & 1.67 & 1.00 & 1.67 & 1.00 & 2.33 & 1.00 & 2.33 \\
& JS & 3.00 & 3.83 & 1.00 & 3.67 & 1.00 & 3.00 & 1.00 & 4.00 & 1.00 & 4.00 \\
\hline
\end{tabular}

Table 2: Front border (FCB) and back border (BCB) closure placement values at the midpoint of intervocalic / $/$ and / $/$ / (left and middle panels), and at the onset, midpoint and offset of $\mathrm{C} 1=/ 1 /$ in the cluster /1t/ (right panel). Data are presented for all speakers of Majorcan, Valencian and Eastern.

\begin{tabular}{|cc|cc|cc|cccccc|}
\hline \multirow{2}{*}{ Dialect } & \multirow{2}{*}{ Speaker } & \multicolumn{2}{|c|}{$/ \mathbf{V I V /}$} & \multicolumn{2}{c|}{$/ \mathbf{V t V} /$} & \multicolumn{2}{c|}{ C1 ons (/lt/) } & \multicolumn{2}{c|}{ C1 mp (/lt/) } & \multicolumn{2}{c|}{ C1 of (/lt/) } \\
& & FCB & BCB & FCB & BCB & FCB & BCB & FCB & BCB & FCB & BCB \\
\hline \multirow{3}{*}{ Majorcan } & BM & 1.00 & 1.24 & 1.00 & 2.14 & 1.00 & 1.00 & 1.00 & 2.43 & 1.00 & 2.86 \\
& MJ & 1.00 & 1.29 & 1.00 & 1.33 & 1.00 & 1.00 & 1.00 & 1.33 & 1.00 & 1.33 \\
& ND & 1.05 & 2.67 & 1.00 & 3.05 & 1.14 & 1.71 & 1.00 & 3.14 & 1.00 & 4.00 \\
& CA & 1.00 & 1.31 & 1.00 & 2.43 & 1.00 & 1.71 & 1.00 & 2.00 & 1.00 & 2.43 \\
\hline \multirow{5}{*}{ Valenciann } & JM & 1.05 & 2.00 & 1.00 & 1.00 & 1.17 & 1.17 & 1.00 & 1.17 & 1.00 & 1.00 \\
& VB & 1.67 & 1.76 & 1.00 & 1.00 & 1.00 & 1.00 & 1.00 & 1.00 & 1.00 & 1.00 \\
& MS & 1.70 & 2.60 & 1.00 & 1.71 & 1.00 & 1.83 & 1.00 & 2.33 & 1.00 & 2.33 \\
& VG & 1.19 & 1.71 & 1.00 & 1.43 & 1.00 & 1.14 & 1.00 & 2.00 & 1.00 & 2.00 \\
& AV & 1.38 & 1.95 & 1.00 & 1.71 & 1.00 & 2.00 & 1.00 & 2.86 & 1.00 & 3.00 \\
\hline \multirow{2}{*}{ Eastern } & DR & 1.00 & 2.50 & 1.00 & 3.60 & 1.00 & 1.20 & 1.00 & 2.80 & 1.00 & 3.80 \\
& JP & 1.67 & 2.50 & 1.00 & 1.67 & 1.00 & 1.00 & 1.00 & 2.00 & 1.00 & 2.67 \\
& JS & 2.67 & 4.00 & 1.00 & 3.67 & 1.00 & 1.67 & 1.00 & 3.00 & 1.00 & 4.00 \\
\hline
\end{tabular}

According to the data in the tables, assimilation (scenario (a); see section 3.2.1) appears to hold for /nt, lt/ for several speakers (/nt/, AR, BM, JM, VB; /lt/, $\mathrm{JM}, \mathrm{VB}$ ). Thus, for example, data for speaker JM show that the back closure border is more retracted for intervocalic $/ \mathrm{n} /$ (1.62) than for intervocalic /t/ (1), and equally anterior at the midpoint and offset of $/ \mathrm{n} /$ before $/ \mathrm{t} /$ in the cluster /nt/ (1) than at the midpoint of intervocalic / $t /$ (1). 
Blending through intermediation (scenario (b); see section 3.2.1) holds for /nt/ (MJ, VG, JP) and /lt/ (MS). Thus, according to speaker MJ, the back closure border values at $\mathrm{C} 1$ midpoint and offset in the cluster $/ \mathrm{nt} /(1.62,1.92)$ are intermediate between those for intervocalic /t/ (1.33) and for intervocalic $/ \mathrm{n} /$ (2.38).

Blending through superposition (scenario (c); see section 3.2.1) involving a larger closure for the cluster than for its two consonants in intervocalic position operates in the case of $/ \mathrm{nt} /$ for speakers ND, CA, MS and JS and in the case of /lt/ for speakers BM, ND, VG and AV. Thus, according to speaker ND, back closure border location values for $/ \mathrm{n} /$ before $/ \mathrm{t} /$ at closure midpoint and offset $(3.36,3.71)$ exceed those for $/ \mathrm{n} /$ and $/ \mathrm{t} /$ in intervocalic position (about 3.1). As pointed out in section 3.2.1, blending through superposition may be also said to apply whenever the closure extent for the cluster matches that for the most widespread intervocalic consonant if this consonant is not $/ t /$. This condition is at work for $/ \mathrm{nt} /$ for speaker AV and for /lt/ for speakers JP and JS, since the closure area for $\mathrm{C} 1=/ \mathrm{n}, 1 /$ in the two clusters is analogous to that for the same consonants in intervocalic position, and that for intervocalic $/ \mathrm{n}, 1 /$ exceeds that for intervocalic $/ \mathrm{t} /$.

The remaining cases are ambiguous. This is so for the clusters $/ \mathrm{nt}$, lt/ for speaker DR and for the cluster /lt/ for speaker CA, where the closure area for $\mathrm{C} 1=/ \mathrm{n} /$ and $\mathrm{C} 1=/ 1 /$ is close or analogous to that for intervocalic $/ \mathrm{t} /$, and that for intervocalic $/ \mathrm{t} /$ is more posterior than that for intervocalic $/ \mathrm{n} /$ and/or $/ 1 /$. The production strategy for $/ \mathrm{lt} /$ for speaker $\mathrm{MJ}$ is also unclear since the closure location for $\mathrm{C} 1=/ 1 /$ in the cluster is as anterior as that for intervocalic $/ 1 /$ and $/ \mathrm{t} /$.

\section{Discussion}

Linguopalatal data on closure location and extent has allowed us to determine the production strategy of consonant clusters composed of dentals, alveolars and alveolopalatals in Majorcan, Valencian and Eastern.

When followed by an alveolopalatal consonant, the alveolar nasal $/ \mathrm{n} /$ undergoes frontward and backward closure expansion, and blending through superposition at about $\mathrm{C} 1$ midpoint, as a general rule. Regressive palatalization is less obvious for clusters with $\mathrm{C} 1=/ 1 /$, mostly so if the alveolar lateral is dark: indeed, while the front closure border achieves maximal fronting early in the cluster, the back closure border may either fall somewhere between that for the two adjacent consonants or else may achieve a more retracted location not earlier than $\mathrm{C} 1$ offset. Blending through superposition may also fail to apply when the articulatory distance between $\mathrm{C} 1$ and $\mathrm{C} 2$ is too large; thus, in Majorcan clusters where $/ \mathrm{n} /$ is palatal rather than alveolopalatal, the final articulatory outcome exhibits either an intermediate configuration between that of $\mathrm{C} 1$ and 
$\mathrm{C} 2$ or else two separate targets. In all cases, closure location at $\mathrm{C} 1$ onset occurs at the alveolar zone and is analogous to that for intervocalic $/ \mathrm{n}, 1 /$. These data indicate that blending through superposition applies naturally when both adjacent consonants are considerably unconstrained and articulated close to each other, while a greater articulatory separation between those consonants or an increase in degree of constraint for one of them may either cause a delay in the blending implementation or else may yield an articulation which is intermediate between the two consonants in the cluster.

A comparison between the degree of back closure border placement for the cluster and for its two consonants reveals that /nt, lt/ may exhibit blending or assimilation depending on the speaker taken into consideration. The presence of a dental place of articulation at cluster onset could be taken as evidence for the two adaptation processes. Mean values across speakers indicate that blending through superposition is the favored strategy and statistical results allow concluding that this strategy applies mostly at $\mathrm{C} 1$ offset. In Valencian, however, blending through intermediation has also been found to occur. Speakers may prefer one strategy over another in both clusters or may split their preference according to cluster, and also favor blending mostly through superposition over assimilation. In view of the small data set submitted to statistical analysis in the present investigation, more experimental evidence will have to be collected in order to ascertain the validity of the production strategies just referred to.

The notion of articulatory blending formulated by Articulatory Phonology has proved useful for dealing with the articulatory outcome of clusters composed of relatively unconstrained front lingual consonants in Catalan. Blending does not necessarily result in the formation of an intermediate articulatory configuration between the two adjacent consonants in the cluster, however. Thus, sequences composed of an alveolar followed by an alveolopalatal consonant favor blending through superposition unless one of the two consonants is particularly constrained (e.g., dark /1/) or the two are articulated far away from each other (e.g., whenever $/ \mathrm{n} /$ is palatal rather than alveolopalatal). Articulatory blending in these clusters is implemented gradually such that its temporal onset does not usually occur at the beginning of the cluster, i.e., closure location at $\mathrm{C} 1$ onset is basically the same as that for the consonant in intervocalic position. The production strategy involved in clusters with a dental C2 is less straightforward though blending through superposition appears to be preferred over assimilation by our Catalan speakers.

Data for other Majorcan clusters with /n, 1/ followed by (alveolo)palatal consonants other than $/ K, \mathrm{n} /$ not submitted to analysis in the present investigation are in agreement with the notion that blending may fail to apply if $\mathrm{C} 1$ is especially constrained and/or if the two adjacent consonants are articulated too far away from each other. Thus, in addition to $/ \mathrm{ln} /$, other clusters starting with a 
strongly dark variety of /1/ may involve two separate targets for $\mathrm{C} 1$ and $\mathrm{C} 2$. This is so for $/ \mathrm{lj} /$ for all speakers and for $/ \mathrm{lc} /$ for speakers BM, MJ and ND, where $/ \mathrm{j} /$ and /c/ exhibit a purely palatal realization (/c/ is an allophone of $/ \mathrm{k} /$ in Majorcan and therefore should be transcribed [c]). If $\mathrm{C} 1$ is unconstrained and $\mathrm{C} 1$ and $\mathrm{C} 2$ are fairly distant articulatorily, as for the cluster/nc/ for the same speakers BM, $\mathrm{MJ}$ and ND, segmental adaptation does not result in blending but in regressive assimilation. In this case, the phonetic outcome [nc] exhibits a palatal, not an alveolopalatal, nasal realization, just as /nk/ may be realized [yk] in many languages.

On the other hand, the final outcomes for the Majorcan clusters $/ \mathrm{nc} /$ and $/ \mathrm{lc} /$ with an alveolopalatal instead of a palatal realization of $/ \mathrm{c} /$, are basically the same as those for $/ \mathrm{n} K /(/ \mathrm{nc} /)$ and for the sequence $/ \mathrm{ln} /$ with a strongly dark variety of $/ 1 /$ and an alveolopalatal variety of $/ \mathrm{n} /(/ \mathrm{lc} /)$. Indeed, data for speaker $\mathrm{CA}$ indicate that the alveolopalatal variety of $/ \mathrm{c} /$ undergoes blending after the relatively unconstrained stop $/ \mathrm{n} /$, and carryover depalatalization involving dorsopalatal contact loss after highly constrained dark /1/.

An open issue is how large the articulatory distance between the two adjacent consonants in the cluster ought to be so that a given sequence composed of an alveolar $\mathrm{C} 1$ and an (alveolo)palatal $\mathrm{C} 2$ undergoes one adaptation process or another. Data reveal that two types of palatal consonants need to be differentiated in this respect, i.e., alveolopalatals which are articulated with the blade and the predorsum and whose place of articulation may coincide partly with that for alveolars, and palatals proper which are basically mediodorsal or medio-postdorsal and involve no alveolar central contact. Clusters with an alveolopalatal C2 may undergo blending (/nc/) or C2 depalatalization $(/ \mathrm{lc} /)$, while those with a palatal $\mathrm{C} 2$ are implemented through regressive assimilation (/nc/) or two successive targets (/lc/).

\section{Acknowledgments}

This research was funded by projects HUM2006-03742 of the Ministry of Education and Science of Spain and FEDER, and 2005SGR864 of the Catalan Government. I would like to thank Aina Espinosa for help with the statistical analysis and to Marzena Zygis and Susanne Fuchs for comments on a previous manuscript version. 


\section{References}

Browman, C.P. \& Goldstein, L. (1989). Articulatory gestures as phonological units. Phonology 6, 201-251.

Browman, C.P. \& Goldstein, L. (1992). Articulatory Phonology: an overview. Phonetica 49, 155-180.

Fowler, C.A. \& Saltzman, E. (1993). Coordination and coarticulation in speech production. Language and Speech 36, 171-195.

Navarro Tomás, T. (1972). Manual de pronunciación española. Madrid: CSIC, $17^{\text {th }}$ edition.

Recasens, D. (2006). Integrating coarticulation, blending and assimilation into a model of articulatory constraints. In: L. Goldstein, D. Whale \& C. Best (eds.). Laboratory Phonology 8. Berlin-New York: Mouton de Gruyter, 611-634.

Recasens, D. \& Espinosa, A. (2006). Articulatory, positional and contextual characteristics of palatal consonants. Evidence from Majorcan Catalan. Journal of Phonetics 34, 295318.

Recasens, D. \& Pallarès, M.D. (2001). Coarticulation, blending and assimilation in Catalan consonant clusters. Journal of Phonetics 29, 273-301.

Recasens, D., Pallarès, M.D. \& Fontdevila, J. (1997). A model of lingual coarticulation based on articulatory constraints. Journal of the Acoustical Society of America 102, 544-561.

Solé, M.J. (2002). Assimilatory processes and aerodynamic factors. In: C. Gussenhoven \& N. Warner (eds.). Laboratory Phonology 7. New York: Mouton de Gruyter, 351-386. 